\title{
Synchronous Ordinary Lipoma and Spindle-Cell Lipoma Diagnosed by Fine Needle Aspiration
}

Dear Dr. Bedrossian:

Although histological examination is by-and-far considered the gold standard for most soft tissue diagnoses, fine needle aspiration (FNA) is an excellent modality to determine the initial characteristics of the lesion in question. To our knowledge, there have been only two reported cases of ordinary lipoma and spindle-cell lipoma occurring at the same time in the same patient; these were both diagnosed by excisional biopsy. ${ }^{1,2}$ We report a rare case in which synchronous ordinary lipoma and spindle-cell lipoma was first diagnosed by FNA.

An 80-yr-old male presented for FNA of two neck masses in work up for basal-cell carcinoma of the scalp. Physical examination revealed the masses to be soft and painless to palpation. FNA of the right posterior neck mass demonstrated a few clusters of mature adipocytes (Fig. 1A) with small, round, and eccentric nuclei with no visible nucleoli, diagnostic of ordinary lipoma. FNA of the midline posterior neck mass demonstrated few cohesive fragments of uniform spindled cells in a myxoid matrix with scattered mast cells (Fig. 1B, C). The spindle-cell nuclei were generally smooth and fusiform; cytoplasm was scant and pale. Rare mature adipocytes are also present. No lipoblasts, mitotic figures, nor nuclear atypia were identified. The aspiration was interpreted as spindle-cell neoplasm, favor spindle-cell lipoma. Three months later, the patient had the excision of these masses along with his scalp basal-cell carcinoma. Grossly the right posterior neck mass was a well-circumscribed $2.0 \mathrm{~cm}$ yellow, lobular adipose tissue. Microscopically, there were mature, uniform fat cells with a delicate, almost inconspicuous vasculature (Fig. 1D), diagnostic of

*Correspondence to: Robert T. Pu, M.D., Ph.D., Department of Pathology, University of Michigan, 1500 E. Medical Center Drive, Room 2G332, Box 0054, Ann Arbor, Michigan, 48109.

E-mail: robertpu@umich.edu

Received 15 July 2005; Accepted 6 October 2005

DOI 10.1002/dc.20444

Published online in Wiley InterScience (www.interscience.wiley.com). ordinary lipoma. The midline posterior neck mass was 2.5 $\mathrm{cm}$, well circumscribed with variegated pink/tan/yellow cut surface. Microscopically, there were thick bands of collagen with scattered lobules of mature adipose tissue (Fig. 1E); spindle cells were positive for CD34 stain (Fig. 1F), diagnostic of spindle-cell lipoma.

We report here what we believe is the first case of FNA diagnosing of coexisting ordinary lipoma and spindle cell lipoma. Histologically, spindle-cell lipoma is at one end of the spindle-cell lipoma/pleomorphic lipoma spectrum. $^{3}$ The entity as a whole is composed of various amounts of mature adipose tissue, spindle cells, collagen, and often with myxoid change. Although any component may predominate, the relative amounts of each tend to be equal. ${ }^{4}$ The spindle cells are usually arranged in short fascicles but can also be randomly distributed. Mast cells are seen in approximately $50 \%$ of specimens. ${ }^{5}$ Almost all tumors are CD34 positive. ${ }^{1,4}$ Cytologically, spindle-cell lipomas show much overlap with other spindle-cell tumors, both benign and malignant. Having knowledge of the histological picture, one can predict the components that will be present in the FNA: adipocytes, spindle cells, collagen, and/or mast cells. ${ }^{3,6-8}$ Other spindle-cell tumors that should be considered in the differential diagnosis include neurogenic tumors, dermatofibrosarcoma protuberans (DFSP), and myxoid tumors. Absence of fat and immunohistochemical staining of the cell-block for CD34 (positive for spindle-cell lipomas and negative for neurogenic tumors) and S100 (negative for spindle-cell lipomas and positive for neurogenic tumors) are critical in making this distinction. Finally, depending on the myxoid nature of the lesion, one must consider various myxoid processes, such as post-traumatic/inflammatory, myxoid liposarcoma, and myxofibrosarcoma. The first of these is characterized by relatively high cellularity, adipocytes of various size and foamy histiocytes. ${ }^{9}$ The two latter malignant sarcomas might pose a diagnostic problem if they represent lowgrade varieties. Location and careful inspection for atypical features, such as lipoblasts, pleomorphism, and prominent vascular fragments, will prove to be beneficial in differenti- 


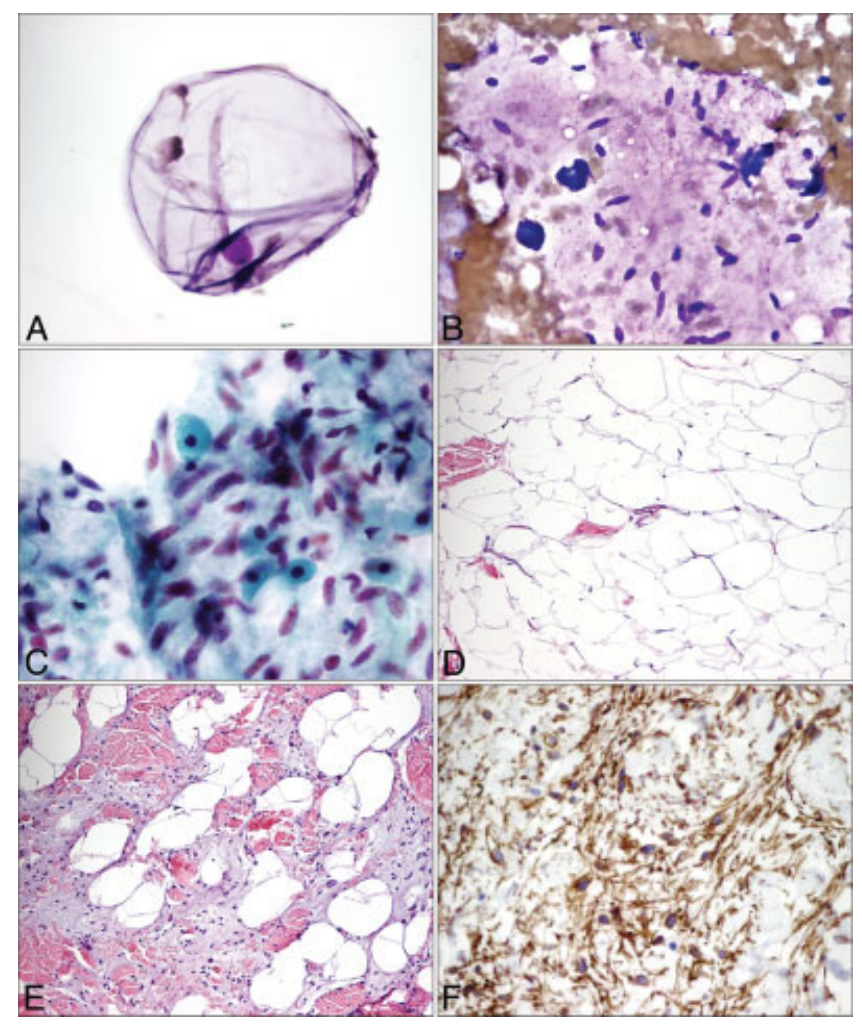

Fig. 1. Representative cytologic and histologic features of the two lesions. A: FNA of the right posterior neck mass showing single adipocyte with small, round, eccentric nuclei and large lipid vacuole (DiffQuik, $1,000 \times)$. B, C: FNA of the midline posterior neck mass showing spindle cells in a myxoid matrix with occasional mast cells (Diff-Quik, $500 \times$ and Papanicolaou, $1,000 \times)$. D: H\&E stain of right posterior neck mass (ordinary lipoma) excision showing regular adipocytes and inconspicuous vasculature $(200 \times)$. E: H\&E stain of the midline posterior neck mass (spindle-cell lipoma) showing thick bundles of collagen admixed with mature adipocytes $(200 \times)$. F: CD34-positive spindle cells in spindle-cell lipoma $(400 \times)$. [Color figure can be viewed in the online issue, which is available at www.interscience.wiley.com.]

ating these from spindle-cell lipoma. Ordinary lipomas, on the other hand, typically pose little diagnostic dilemma, either histologically or cytologically. Differentiating between ordinary lipoma and well-differentiated liposarcoma can be difficult; however, findings such as multivacuolated cytoplasm and lipophages might help in distinguishing between the two. In addition, pertinent clinical history such as patient age, tumor location, and prior diagnoses will also aid in separating the two.

The relationship between other illnesses/neoplasms and spindle-cell lipomas has been considered by others; however, no direct connection has been suggested nor implied. Fanburg-Smith et al. reported two patients with concurrent spindle-cell lipomas and basal-cell carcinomas. ${ }^{10}$ As mentioned earlier, our patient was initially being worked up for basal-cell carcinoma when these two neck masses were noticed. A search of our database for "spindle cell lipoma" from 1995-2005 revealed 22 diagnoses of spindle-cell lipomas in 21 patients. Four of these 21 patients, including the current patient, had another neoplasm either concurrently or subsequently.

In summary, we report a case of coexisting ordinary lipoma and spindle-cell lipoma initially diagnosed by FNA. The FNA differential diagnosis for spindle-cell lipoma can appear intimidating at first; however, careful examination of the smear and knowledge of the histology and epidemiology of this lipoma-variant will aid in the correct diagnosis.

\author{
Masood A. Siddiqui, M.D. \\ Lyndon $\mathrm{Su}$, M.D. \\ Claire W. Michael, M.D. \\ Robert T. Pu, M.D., Ph.D.* \\ Department of Pathology \\ University of Michigan Medical Center \\ Ann Arbor, Michigan
}

\section{References}

1. Sakai H, Kuoda K, Hara D, Tajima S. Coexistence of spindle cell lipoma and ordinary lipoma. J Dermatol 2004;31:831-834.

2. Usta U, Turkman E, Mizrak B, Yildiz D, Guzel Z. Spindle cell lipoma in an intramuscular lipoma. Pathol Int 2004;54:734-739.

3. Enzinger FM and Weiss SW. Benign lipomatous tumors. In: Enzinger FM, Weiss SW, editors. Soft Tissue Tumors. 4th ed. St. Louis, MO: CV Mosby; 1998. p 590.

4. Domanski HA, Carlen B, Jonsson K, Mertens F, Akerman M. Distinct Cytologic Features of Spindle Cell Lipoma. A cytologic-histologic study with clinical, radiologic, electron microscopic, and cytogenetic correlations. Cancer 2001;93:381-389.

5. Miettinen MM and Mandahl N. Spindle cell lipoma/Pleomorphic lipoma. In: Fletcher CDM, Unni KK, and Mertens F, editors. World Health Organization Classification of Tumours, Pathology and Genetics: Tumours of Soft Tissue and Bone. Lyon, France: IARC Press; 2002. p 31-32.

6. Layfield LJ, Anders KH, Glasgow BJ, Mirra JM. Fine-needle aspiration of primary soft-tissue lesions. Arch Pathol Lab Med 1986; 110:420-424.

7. Agoff SN, Folpe AL, Grieco VS, Garcia RL. Spindle cell lipoma of the oral cavity. Report of a rare intramuscular case with fine needle aspiration findings. ACTA Cytol 2001;45:93-98.

8. Fasig JH, Robinson RA, McCulloch TM, Fletcher MS, Miller CK. Spindle cell lipoma of the parotid: fine-needle aspiration and histologic findings. Arch Pathol Lab Med 2001;125:820-821.

9. DeMay RM. The Art \& Science of Cytopathology, Aspiration Cytology. Chicago, IL: ASCP Press; 1996. 1280 p.

10. Fanburg-Smith JC, Devaney KO, Miettinen M, Weiss SW Multiple Spindle Cell Lipomas. Am J Surg Pathol 1998;22:40-48. 